\title{
Imigrante brasileiro em Portugal - "pé de passada"
}

\author{
Por: Eduardo Gabriel *
}

Por ocasião de minha pesquisa de doutorado "Catolicismo carismático brasileiro em Portugal", por duas vezes estive em Portugal em pesquisa de campo. De modo particular, fiz pesquisas na cidade de Leiria, localizada no centro do país. Os períodos de estadia foram: dezembro de 2006 e janeiro de 2007, primeira etapa, e, em 2008, de março até novembro. Antes de iniciar a pesquisa de campo, navegando pela internet para obter informações, depareime com uma comunidade virtual na rede social Orkut, criada por Augusto, com a finalidade de auxiliar os imigrantes em suas dúvidas sobre a legislação e informações sobre política, economia e vida social em Portugal. Sabendo da importância dessas redes para os imigrantes e da sua crescente utilização, bem como da sua transformação, em alguns casos, em verdadeiras armadilhas de exploração dos próprios imigrantes, quando não de fomento ao tráfico de pessoas, decidi-me a conversar com Augusto.

Ocontato e a aproximação com Augusto foram mais fáceis do que imaginava. Usando do espaço da própria comunidade, escrevi manifestando meu interesse em conversar pessoalmente com ele. $\mathrm{O}$ retorno foi imediato e, manifestando grande entusiasmo, disse estar pronto para um bate-papo. Para minha grande sorte, ele morava na mesma cidade onde eu me encontrava. Combinamos dia, horário e local para uma entrevista. $O$ encontro transcorreu numa lanchonete da cidade, uma vez que para lá teria que levar os filhos e a esposa Rosa. Não fiz objeção nenhuma e, conforme combinado, nos encontramos.

\footnotetext{
* Doutor em Sociologia pela USP
} 
Augusto é brasileiro e Rosa é filha de portugueses, mas nascida em Angola. Conheceram-se no Brasil, para onde os pais de Rosa migraram por um período após terem deixado Angola e, atualmente, moram em Leiria, região central do país.

Por fim, devo um esclarecimento quanto à expressão "pé de passada". Quem a proferiu foi um padre português, também de Leiria, quando me disse: “Os brasileiros sempre estão a chegar e a partir, são pés de passadas...", expressão que sintetiza a ideia com a qual Augusto conclui a sua fala.
E: Eduardo
R: Rosa
A: Augusto

\section{Trajetória imigrante}

E: Você é portuguesa, mas já tem uma história de migrante, inclusive morou no Brasil. Por quanto tempo viveu lá?

R: Dezoito anos. Eu nasci em Angola, Luanda, mas o sonho do meu pai era ir para o Brasil, e surgiu esta oportunidade quando houve a guerra. Ao invés de ir para Portugal, com a família, fomos para o Brasil.

E: Isso foi em que ano?

R: [19]75.

E: A guerra foi em que ano?

R: Quando nós saímos de lá, ainda tinha guerra.

E: Ao invés de voltarem para Portugal, vocês foram para o Brasil.

R: Os meus pais são portugueses mesmo, e minha família toda está aqui. Quando saímos de Angola o meu pai quis conhecer o Brasil, e foi direto para lá, eu e minha mãe ainda viemos para Portugal, e ficamos aqui oito ou nove meses, para que eu pudesse conhecer meus parentes que ainda não conhecia, e também a minha avó, mãe da minha mãe. Depois de nove meses, chegamos ao Brasil, que foi no dia de carnaval, eu lembro que foi dia 28 de fevereiro, justamente naquela confusão, e o meu pai nos levou logo para ver o carnaval. Ficamos no Brasil 18 anos, em Santana, São Paulo, Zona Norte.

\section{E: Você chegou ao Brasil com quantos anos?}

R: Eu cheguei entre os 9 para 10 anos, e fiquei até os 28 anos. Chegou uma época que meus pais estavam querendo vir pra cá, na terra deles, e eu não queria, pois tinha meus amigos, a faculdade, estudei na Faculdade Santana, fiz o curso de Administração de Empresas, que não valeu nada, mas fiz o curso, comecei, não gostei, e quis parar, porém, meus pais não deixaram, o que não adiantou nada, porque hoje não exerço minha profissão. Nessa época que meus pais queriam 
vir pra cá, eu rezava para que eles não conseguissem vender a casa para eu não vir para cá.

\section{E: Os seus pais trabalhavam com o quê?}

R: Meu pai trabalhava com bilhetes da loteria lá na Praça da Sé, aquelas barracas que o pessoal vendia bilhetes; minha mãe era costureira, trabalhava em casa, e eu também tinha o meu trabalho. Meus pais não estavam conseguindo vender a casa, porque não é fácil vender uma casa, e naquela época a situação já não estava boa. Nesse meio tempo, eu conheci o Augusto e ele falou que o sonho dele era sair do Brasil, conhecer outros lugares. Como os meus pais sempre quiseram voltar para Portugal, na hora em que ele disse que não se importava em vir...

\section{E: Os seus pais são de Leiria mesmo?}

R: Não, meus pais são de Vila Real, Trás-os-Montes, lá do frio, onde até neve tem. Hoje meus pais moram em Leiria também, pois moramos aqui. Então viemos do Brasil, ficamos uns anos aqui, mas tínhamos a intenção de voltar ao Brasil. Chegamos em [19]93 cá em Portugal, quando casamos. Casamos no Brasil e viemos! Em [19]96 fomos lá de férias, e ficamos dois meses. Em [19]97 nós voltamos para morar definitivamente, sendo que também não tínhamos grandes coisas aqui, porque a gente nunca pensou em ter nada, pois a nossa cabeça era sempre voltar, só que ficamos lá [Brasil] uns oito meses, e as coisas voltaram para trás por conta da violência e tudo. Resolvemos voltar para Portugal para sempre, não deixar passar muito tempo, principalmente para o Augusto que trabalha com programa de computador. Então resolvemos voltar e ele continuou o que já tinha.

E: $E$ você, faz o quê?

R: Eu cuido de uma senhora de idade. Trabalhei na "loja dos 300", depois fomos para o Brasil em [19]97, montamos uma "loja dos 300 lá".

E: O que é "loja dos 300"?

R: Aquelas coisas baratinhas, 1,50. Quando nós fomos de férias, em [19]96, não havia nenhuma, mas quando fomos em [19]97, estava cheio já.

E: E agora, qual a relação com o Brasil?

A: Nós já estamos inadaptados ao Brasil.

E: Já são portugueses...

A: Já, já...

\section{Imigrantes em Portugal}

A: Nós acompanhamos o início da imigração dos ucranianos e dos russos em Portugal. Quando chegamos, em [19]93, ainda não havia por aqui nem russos e 
nem ucranianos, sendo que eles começaram a chegar mais ou menos em [19]97, mesmo aos pouquinhos! Começamos a ver que eram estrangeiros, e depois a imigração russa e ucraniana começou a aumentar, e a partir de [19]98, eles chegaram com força.

E: Como você está ligado a estes grupos imigrantes, pois eu vi no seu Orkut que tem ajudado as pessoas?

A: A minha profissão não tem nada a ver com isso. Eu trabalho com programas de arquitetura, e estou a fazer licenciatura de Arquitetura, trabalho no desenvolvimento de software. Mas notei que realmente as pessoas têm dificuldades de informações, e algumas dessas informações estão dispersas.

\section{E: Mas em algum momento você teve necessidade pessoal para isso?}

A: Sempre me interessei por isso, pois também sou casado com uma portuguesa, e eu tive que correr com os papéis da documentação, e vi realmente que é bastante difícil. No meu caso, eu tive que ir para a Espanha colocar os papéis no consulado, e sei das dificuldades das pessoas estarem sempre precisando de informações. Simplesmente notei este detalhe, e comecei a participar de algumas comunidades no Orkut, e vi que as pessoas precisavam de informação, mas depois aquilo se perdia, e logo entrava uma nova pessoa com a mesma dúvida. Eu entrei em contato com várias pessoas que eram moderadoras de comunidades, e propus esta ideia: "porque vocês não criam uma parte para as pessoas que já estão resolvidas, as pessoas chegam e veem se aquilo já está respondido ou não", isto seria bom para todos. De tantos moderadores que eu falei, nenhum respondeu. Sendo assim, eu tentei criar a minha comunidade, mas não conhecia ninguém, não tinha contato nenhum, e fiz mesmo por boa vontade.

\section{$\mathrm{E}:$ Eu pensei que você tivesse alguma ligação institucional com algum órgão.}

A: Não, não, eu nunca imaginei criar comunidade, nem ser moderador, nem nada. Depois, aos poucos, eu vi que a maior parte dos moderadores das comunidades estavam ligados a alguma coisa, ou do ramo de direito, ou do ramo de legalização de imigrantes, e algumas dessas comunidades funcionam até como angariação de clientes.

\section{E: Explique melhor isso, por favor.}

A: Estão ligados a escritórios de advocacia.

E: Mas escritórios de advocacia de portugueses ou de brasileiros que estão em Portugal?

A: As duas coisas. Eu descobri que alguns não tinham a intenção de facilitar, mas sim de dificultar. O brasileiro sempre tem aquela coisa de ajudar de "boa vontade", e cria um vínculo com a pessoa. A partir disso, se essa pessoa precisar 
de alguma coisa, ela vai tratar com alguém que ela confia, e aí lhe é indicado: "eu tenho um fulano em Lisboa que pode tratar disso". "Ótimo, então vamos lá..."

\section{E: Você conhece pessoas assim?}

A: Conheço! É até decepcionante, porque uma dessas, uma mulher, se fazia passar por advogada e não era, estava ali só para angariar, e até era tratada como doutora; era uma santa mulher, porque estava sempre disponível, estava sempre dando informações, estava ajudando as pessoas, mas na realidade não estava ajudando nada, estava olhando os interesses dela. Comecei a achar estranho! Ela tinha uma comunidade parecida com a minha, "Defesa do Imigrante", ou coisa assim, e eu me identifiquei um bocado com aquela comunidade, pois ela estava sempre prestativa, sempre respondendo as perguntas. Eu comecei a mandar algumas mensagens para ela, a fim de saber se nós não poderíamos trocar algumas informações. Por exemplo, questões que tinham sido resolvidas na minha comunidade podiam ser passadas na dela, e vice-versa, mas ela não me respondia, e achei estranho: "uma pessoa que é tão prestativa com as pessoas, tão paciente, não me responde?" Depois eu vim a descobrir, e soube que ela não é advogada, tem até um processo criminal em cima, e que estava ali somente para angariar as pessoas. Descobri mesmo porque saiu na comunidade esta informação, e depois ela dizendo a verdade, que ela não poderia exercer esta atividade aqui em Portugal.

\section{E: E agora, tem notícias desta comunidade?}

A: Não sei, porque eu me afastei um bocado disto, pois foi uma quebra de confiança.

\section{E: Sabe se ela estava ligada a algum grupo?}

A: Que eu saiba, não! Estava mesmo ligada a negócios, porque nessas comunidades há sempre muitas pessoas, mil, duas mil. Na minha tem 1.060.

E: E qual é a maior dúvida que as pessoas mais querem saber?

A: É a legalização.

E: Todos querem se legalizar...

A: Sim, sim, querem sair do Brasil já com o visto, e o próprio consulado não informa corretamente.

R: Mas isso é normal aqui, qualquer repartição que você vá, um fala uma coisa, outro fala outra, isso no mesmo lugar. Hoje em dia não sei como é.

A: A maior procura é de pessoas, ou que estão tratando de legalizações, ou naturalizações, e como há muita procura, o governo não tem interesse em abrir as portas, porque a economia está em crise severa, pois desde que nós estamos aqui, nunca esteve numa crise desta, nunca esteve pior. A economia do país está 
numa recessão mesmo. Houve momentos, antes de 2002, por exemplo, em que havia liquidações, e as lojas ficavam vazias, porque as pessoas compravam tudo. Para você ter uma ideia, não sei se já observou, aqui os carros têm a data da matrícula, o ano que o carro foi matriculado está inscrito na placa, então a gente consegue ver por aí, nós andávamos por aí e víamos, em 1999 e 2000, era um carro atrás do outro, pois as pessoas sempre estavam comprando, nós víamos pelas placas. No início do mês já começava a aparecer os carros daquele mês, e no mês seguinte também, e era assim, uma loucura, pois as pessoas trocavam de carro como trocavam de roupa. Além disso, trocavam de apartamentos, embora tivessem um apartamento em boas condições, mas se aquilo já não dava mais, vendia e já comprava outro porque era mais perto do serviço, só por capricho, pois a economia estava numa ascensão, e foi nessa época que vieram os ucranianos e os russos. Os prédios estavam a construir, havia só os esqueletos dos prédios, e se chegávamos para comprar, já estavam todos vendidos. Nós compramos o nosso apartamento com sufoco, só conseguimos comprar na planta, pronto não havia.

E: Eu li, esta semana, no jornal, que em Lisboa existem duzentos e tantos...

A: Vagos! Mas isso é agora, porque começou em 2002 esta queda.

E: As pessoas estão tendo que se desfazer dos apartamentos, é isso?

A: Não! Para construir, as pessoas se endividaram nas épocas das "vacas gordas", e agora não têm condições de pagar, pois naquela época as pessoas podiam fazer uma dívida de mil euros para pagar a prestação de um apartamento, pois havia facilidade de crédito por conta da economia que estava em ascensão; as pessoas com bons empregos. Depois disso foi caindo, o próprio banco dificultou; antes os juros eram mais baixos, agora os juros subiram bastante, e antes havia também o crédito bonificado, não há mais, o governo pagava uma parte dos juros. Então, antes era facilíssimo comprar um apartamento, até mesmo para imigrantes.

E: Eu não tenho ideia, qual o preço de um apartamento aqui?

A: Cem mil euros, um apartamento razoável.

E: E um carro, aqui?

A: Novo, está a partir de quinze mil, um carro popular, Pegout.

E: Em Portugal, compra-se como, há financiamentos?

A: Há tudo, inclusive pode comprar com visto de residência, na época eu comprei meu apartamento com visto de residência.

E: Mas, os brasileiros conseguem fazer isso hoje?

A: As leis estão sempre a mudar, naquela altura havia facilidade de crédito. Nós compramos nosso apartamento sem penhor, sem nada, hoje possivelmente seria 
só com penhor, pois houve uma restrição de crédito, um aperto, um arrocho, pois as pessoas se endividaram muito, ao ponto em que alguns perderam 0 apartamento. $O$ país mudou muito. Hoje o país é outro, em seis anos mudou completamente.

E: Gostaria que me dissesse um pouco disso, quando chegou aqui que Portugal, você viu que país?

\section{R: 1993.}

A: Nós vimos três países diferentes. O primeiro foi um país um pouco antiquado, arcaico ainda, em [19]93, pois era um país sossegado, e não era um país arrojado de crescimento acelerado. Isto foi sossegado para nós criarmos os nossos filhos e termos uma vida razoável, e também com relação à segurança, porque não havia ainda muita coisa conturbada da violência. Portanto, em 1993 víamos aqui um país sossegado. Depois, a partir de 1997, o país entrou numa taxa de crescimento aceleradíssimo. Mas começou a crescer mesmo foi quando teve a Expo 98. A partir daí a autoestima do português subiu de tal maneira... Você ouviu falar que teve a Exposição Mundial em 1998, que foi no Parque das Nações. Foi nesta altura, quando começaram a construir a Expo, que apareceu a questão se Portugal tinha dinheiro para tudo aquilo, pois isso era coisa de país rico. Mas aquele evento colocou a autoestima de Portugal lá em cima, porque foi a melhor Exposição Mundial que teve de todos os tempos, sendo que a última tinha sido em Sevilha, quatro anos atrás e tinha sido um fracasso. Porém, em Portugal, foi realmente uma coisa fantástica, tanto que você vê aquilo hoje e está lindo mesmo, não é!? A partir disso, Portugal entrou numa ascensão econômica e a própria moral dos portugueses subiu muito, porque o português sempre é um bocado pessimista, sempre notamos isto.

R: Chegamos em [19]93 e já choravam que a coisa estava mal.

A: As pessoas sempre foram muito negativas, mas em [19]98 foi o contrário, as pessoas começaram a ter mais autoestima. A construção civil começou a aumentar, as pessoas começaram a comprar apartamentos, casa na praia, etc. Portugal se candidatou à organização do Euro 2004, contra a Espanha, e ninguém achava que Portugal ia vencer a Espanha numa disputa para sediar um evento, a Eurocopa, mas eles foram e derrotaram a Espanha. Resultado: estádios novos para todo lado. A Eurocopa foi em 2004, mas a aprovação da candidatura foi em 2002, dois anos antes, e a partir disso já começaram a construir estádios fabulosos, e o do Porto é lindíssimo, o Estádio do Dragão, por exemplo.

R: O nosso foi o de Leiria.

E: Houve campeonato aqui?

A: Sim, dois ou três jogos só. Então foi este Portugal que nós conhecemos; primeiro o Portugal antiquado, que havia nesta altura até [19]97, com 
pouquíssimos brasileiros aqui, muito pouco brasileiro, quase todos os brasileiros que nós encontrávamos eram parecidos conosco, que vieram para ter uma vida mais tranquila, e não víamos brasileiros que trabalhassem em McDonald's, na construção civil, nos restaurantes, etc. Algumas vezes você encontrava um no restaurante, a servir mesa, mas era por opção de vida, não porque o Brasil estava mal, queriam apenas mais traquilidade de vida. Em [19]97, quando começou esta ascensão, começou também a vir os homens para as obras, e aí começou a se ver muitos brasileiros, a migração maciça de brasileiros com incentivo do governo.

\section{E: Qual o incentivo?}

A: Houve um incentivo do próprio governo, pois era preciso de mão de obra, porque a economia estava crescendo a uma taxa daquelas, e para isso os brasileiros eram os preferenciais. É verdade que os imigrantes do Leste também vieram com força.

\section{E: Também com o incentivo do governo?}

A: Sim, pois quando a economia está em expansão, o governo facilita a obtenção do visto. Para você ter uma ideia, um trabalhador da construção civil estava a terminar uma obra, chegava um empreiteiro, e dizia: "deixa seu telefone que à noite quero conversar com você", e chegava a telefonar oferecendo salário maior, porque não havia mão de obra. Esses anos de 1998 até 2002, Portugal era outro país.

\section{$\mathrm{E}:$ E você, o que estava fazendo neste momento?}

A: Eu estava ligado à área de projetos de construção, fazia projetos e programas, como faço agora.

\section{E: E aquele momento estava bastante bom?}

A: Estava, estava, foi a altura que nós compramos o apartamento.

R: Se fosse agora para comprar, não comprávamos nada.

A: Compramos o apartamento, construímos um sótão, nós temos um apartamento que é tipo duplex, e o de cima é um sótão que tem um escritório, uma cozinha, um banheiro, uma sala, e foi tudo nesta altura, pois enquanto muitas pessoas aproveitaram para trocar de carro, nós investimos bastante no nosso patrimônio. Mesmo para os passeios, nós nunca fomos ao Algarve, e nunca tiramos férias a sério. A vida de imigrante é completamente diferente da vida do português.

\section{E: Depois a boa situação começa a cair, mas por quê?}

A: Porque era uma situação das pessoas estarem a se endividar para sempre. Chegou uma altura que as casas aqui estavam a custar mais caras do que na Espanha, quer dizer, com a especulação, houve muita procura, e os preços 
estavam a subir. Para você ter uma ideia, nós pagávamos ágio para comprar um apartamento.

\section{E: Nesta altura já havia muitos brasileiros aqui?}

A: Sim, nós encontramos alguns que tiveram dificuldades, que perderam o emprego, foram embora e depois muitos voltaram, pois a maior parte dos brasileiros volta.

R: Pelo menos conhecemos alguns que trabalhavam na construção civil, foram, e voltaram.

A: Foram para o Brasil e depois voltaram para cá novamente.

R: Juntaram dinheiro para comprar uma casa, ter uma vida estável, mas retornaram, e trouxeram a família.

\section{Imigrante conhece imigrante}

A: Conhecemos muita gente que vai e volta, quando o imigrante sai do Brasil, a vida da pessoa sempre fica dividida. Aqui é muito bom, mas também falta muita coisa, é diferente, tudo, e a adaptação é difícil.

R: Os portugueses aqui estão muito endividados, eles gastam mais do que ganham. O pessoal não abdica de tirar férias, de ir para o Algarve, ir para outros países de férias. Quando voltam das férias de verão, logo a seguir começam as aulas, e eles fazem crédito [empréstimo] para pagar o material das crianças.

A: Isto está relacionado com o crédito imobiliário, pois para uma pessoa comprar um apartamento, o crédito vai até os quarenta anos, então muita gente que fez crédito no período bom, está a pagar aqui uma fortuna. Por exemplo, um casal usa o salário todo para pagar a prestação, mas se fosse fazer esta dívida hoje, não faria, porque é inviável, mas naquela altura fizeram, porque a economia estava em ascensão, e os salários eram melhores do que hoje. Em suma, hoje muita gente está endividada, e isto não dá para se perceber, só morando aqui mesmo.

E: Qual é a "aparência" do brasileiro para o português?

A: Não é das melhores...

R: Aqui, nota-se logo quando é brasileiro: "chinelinho no pé", "camiseta cavada".

A: Isso é um estereótipo, não é!

R: Até entre nós dizemos que é brasileiro: "aquele é brasileiro", "aquela é brasileira", até mesmo pelo jeito de andar nós notamos.

A: No jeito de andar, nota-se. A minha sobrinha esteve aqui 45 dias, e aonde ela ia, todo mundo sabia que ela era brasileira, ainda que ela não é morena, e 
fisicamente poderia ser portuguesa. Fisicamente não diz nada, mas o jeito de andar, o jeito de falar, sim.

\section{E: Mas isso influencia o quê, por exemplo?}

A: Os portugueses gostam muito do brasileiro, porém, tem uma relação tensa, e eles acham que quase toda mulher brasileira está ligada a esta área de que são fáceis.

\section{E: Como foi o famoso caso das "Mães de Bragança"?}

A: É verdade, foram os bordéis, perto de Vila Real. Nos bordéis havia somente brasileiras trabalhando, e elas movimentavam a economia da cidade, eram as que usavam mais os salões de cabeleireiro, centro de estética, os táxis, e as mulheres sentiram-se incomodadas, porque Bragança é um bocado rural. Então, as portuguesas, as mães, fizeram um movimento para ver se expulsavam as brasileiras, e realmente a polícia foi nos bordéis e fechou aquilo tudo. Porém, elas se mudaram para a Espanha e ficaram bem ali, $60 \mathrm{~km}$ de distância, bem fronteira. No final das contas, a população achou que aquilo foi ruim para a economia da cidade, que quebrou um bocado. Os taxistas ficaram sem serviço algum, por exemplo.

\section{E: E hoje, os brasileiros estão fazendo o quê aqui?}

A: Estão dispersos, a maior parte trabalha no setor de restauração [restaurantes], e construção civil. Mas é mais na restauração mesmo, se for a Lisboa vai ver muitos brasileiros nos cafés, bares, restaurantes, servindo no balcão, McDonald's, etc.

E: E você sofreu algum preconceito inicial? Como foi sua inserção aqui na comunidade europeia?

A: Foi boa! Naquele tempo o preconceito contra brasileiro não era tão grande quanto agora, essa primeira fase, de [19]93 até [19]97, o brasileiro era até bem-visto aqui, e as pessoas gostavam do nosso sotaque, pois os brasileiros que vinham eram mais selecionados. Houve uma polêmica na altura em que nós chegamos, que foi com os dentistas brasileiros, mas isso foi uma coisa de classe profissional, porque para ser médico dentista aqui, tem que ter o curso de medicina e com especialização em medicina dentária. Porém, lá no Brasil, não, e como o brasileiro era mais carismático com as pessoas, os dentistas portugueses acharam que os brasileiros estavam a tirar um pouco a clientela deles, então houve este choque de classe profissional, mas a própria legislação não colocava impedimentos. O resultado é que eles endureceram um bocado, a associação dos médicos dentistas, mas não foi da população. Por parte da população, se houvesse um médico dentista português e um brasileiro, às vezes era capaz de optar por um brasileiro, porque achava que o brasileiro era mais amigo, mais cuidadoso, etc., e foi isto que vimos neste primeiro período. Depois foi o da Igreja Universal, no Coliseu, do Porto. Mas o grande preconceito contra brasileiros foi 
quando começou esta grande migração no período de [19]97 até 2002, e as pessoas começaram a ficar estafadas: "brasileiros, brasileiros, brasileiros", mas ainda houve uma tolerância grande. A economia entrou em crise, as pessoas começaram a perder empregos, os portugueses começaram a ter dificuldades, e neste contexto os imigrantes são os primeiros a pagar: "estão a tirar os nossos empregos".

\section{E: Você sofreu alguma coisa por ser brasileiro?}

A: Sempre há, sempre há, e até hoje há, vai ser sempre, mas não é mal, é uma coisa natural, acho que qualquer país que recebe imigrante tem este problema. Um dia desses, eu liguei para um gabinete, atendeu a secretária, e eu queria falar com tal pessoa, mas eu consegui ouvir a conversa ao fundo, e ela falou: "é aquele tal brasileiro que veio aqui", e o outro ao fundo: "não, não quero falar com aquele brasileiro". Quando ela me retornou, disse-me: "ele está em reunião", e eu disse: "olha, não precisa dizer mais nada, eu consegui ouvir tudo"! Isto foi há duas semanas, o que é perfeitamente compreensível, pois no Brasil também temos preconceitos contra imigrantes, isso é natural.

E: Você tem contatos com outros brasileiros aqui, casais de brasileiros, etc.?

A: Não! Temos pouquíssimas amizades ao longo desses anos, pois fomos nos afastando. Notamos que há esta coisa, quando há interesse comum, as pessoas se aproximam, e quando não há este interesse as pessoas se afastam, e isso já vem do Brasil, este individualismo.

R: Eu pelo menos não achava que lá era assim.

A: Mas aqui nota-se isso. O exemplo que eu estava dando dos portugueses, em qualquer lugar que formos da França, basta ir numa cidadezinha pequena, e haverá uma associação de portugueses. Por que aqui não há associações de brasileiros?... Só há a Casa do Brasil. Mas, por outro lado, há uma forte associação de cabo-verdianos.

E: Mas isso não é um pouco o medo das pessoas se organizarem, sendo que há muitos ilegais, e talvez a forma de se reunir acaba sendo um pouco fácil do governo encontrar?

A: Eu acho que não, porque há outras comunidades que se reúnem, até os próprios ucranianos que chegaram aqui tinham comunidade, rádio, jornais, mas os brasileiros não têm nada. Na verdade, há alguma coisa, mas sempre tudo muito fragmentado, não há nada daquela coisa que vingue.

\section{E: Mas qual é a dinâmica dessas associações de imigrantes?}

A: Quando há problemas diplomáticos, geralmente é a Associação dos guineenses que toma a frente para resolver, e olha que é um país pequeno. Houve um problema sério em Portugal; estavam chegando tantos imigrantes ilegais aqui, 
e as autoridades colocaram esta população em containeres adaptados, lá no aeroporto, antes de desembarcar. Um repórter entrou no aeroporto, no Porto, e as pessoas estavam sendo alojadas lá, sem condições alguma, antes de poder embarcar de volta, e também estava cheio de brasileiros lá dentro, pessoas com crianças e tudo. Quem interveio nessa situação? Não foi nenhuma associação de brasileiros, foi a Associação guineense.

\section{E: Quando foi isso?}

R: Em 2004. Guiné, que é um país pequeno, tem mais representação institucional do que as instituições brasileiras. Aqui a comunidade de brasileiros é muito desagregada, muito mal vista. Um brasileiro sempre quer passar a perna no outro, quer tirar vantagem, e, infelizmente, é o que a gente nota. Voltando ao exemplo dos portugueses, em qualquer lugar você vê uma comunidade de portugueses, na Alemanha, na Suíça, na França, pode procurar que vai encontrar uma associação forte. Aqui em Leiria deveria haver uma de brasileiros, mas para haver isto, o que é necessário? É necessário alguém que seja responsável por isto. Mas não se faz nada sem dinheiro, é preciso que as pessoas se organizem para haver um caixa. Quando começa a envolver dinheiro, já começa haver desconfiança, e aí se o fulano trocou de carro: "olha, o presidente da associação já trocou de carro, trocou o apartamento, opa, estamos a pagar, será que ele está...?" É o que acontece; as pessoas estão ali a vestir a camisa e outras estão ali a puxar o tapete, isso é muito ruim! Já nota-se porque nada vinga. Porém, boa vontade, em um jogo do Brasil, por exemplo, ouve-se: "vamos nos reunir para assistir o jogo!?", e todos vão lá, pois é uma coisa sem compromisso. Mas se for isto: "vamos nos reunir para montarmos uma associação?", as respostas dirão: "agora não", "é preciso responsabilidade", "é preciso arrendar um espaço", "precisa de um nome", "precisa dedicar horas do seu trabalho para ir lá de forma voluntária", e as pessoas já não estão para isto.

\section{E: Eu não imaginava que houvesse esta situação.}

A: Há uma desconfiança muito grande, tanto que na minha comunidade do Orkut as pessoas das outras comunidades querem saber meu interesse nisso. Eu vi um comentário de um desses moderadores de comunidade que escreveu: "tem um cara de tal comunidade, que é um bocado autoritário". Pois na minha comunidade eu tento manter um controle daquilo que é colocado, não deixo as pessoas colocarem informações que não são confiáveis. E este moderador escreveu mais sobre o meu trabalho: "esta referida pessoa, eu ainda não sei o interesse dela, mas eu estou a tentar descobrir qual o interesse dela". Então, é tudo assim, é muita desconfiança, mas até certo ponto com razão, porque a gente tem visto coisas de brasileiros que são incríveis.

\section{E: Para terminar, qual o maior problema do imigrante aqui?}

R: O problema maior é a saudade da família. 
A: É tudo! Conseguir emprego é difícil, o salário que pagam não dá para ter uma vida que um português tem, e uma pessoa com um salário mínimo aqui não consegue viver.

R: Os brasileiros que trabalham aqui se juntam para conseguir pagar o aluguel do apartamento. É preciso de quatro ou cinco pessoas para conseguir pagar.

A: As pessoas começam a ver que com o tipo de sacrifício que estão a fazer aqui, elas não conseguirão comprar um apartamento, um carro bom como um português, não vão passar férias. Chegam a uma conclusão: "eu estou aqui, mas no Brasil eu ganhava pouco e tinha família, tinha férias, tinha meu carrinho". Para você ter um carro aqui, o custo é tremendo, o seguro aqui é obrigatório, fora os impostos de selo, a gasolina que é caríssima, etc. Então, os imigrantes têm que andar a pé, e com uma situação assim, não vale a pena. O que fazer? Trabalhando, trabalhando, e o dinheiro não dá para pagar as contas: "eu vou embora"! Tem muita gente indo embora, mas tem gente nova chegando também. 
